\title{
REPRESENTANDO LA INFERENCIA DE HECHOS EN EL ÁMBITO JURÍDICO
}

\author{
Peter Tillers* \\ Cardozo School of Law, Yeshiva University
}

RESUMEN. El objeto del artículo es hacer un análisis de las complejidades que surgen cuando se intenta representar gráficamente las inferencias fácticas en el ámbito jurídico y proponer una serie de criterios que pueden servir de guía para cualquier intento de desarrollar un sistema adecuado de representación de inferencias. El prof. Tillers parte del análisis de las inferencias más simples, para sucesivamente mostrar al lector cómo es fácil llegar a situaciones en que la representación visual en el ámbito jurídico se hace muy compleja, de modo que sin un instrumento de representación adecuado se hace imposible de manejar. El prof. Tillers sostiene que para que las representaciones gráficas de las inferencias en el ámbito jurídico sean de utilidad, además de una notación adecuada, deben estar estructuradas del mismo modo que el cerebro organiza los pensamientos, a fin de que la representación gráfica fomente el análisis heurístico del material disponible.

Palabras clave: representación de inferencias prácticas.

ABSTRACT. The purpose of this paper is to analyse the complexities that arise when you try to picture the factual inferences in the legal field. In addition, it proposes a set of criteria that can serve as a guide for any attempt to develop an appropriate system to represent the inferences. Prof. Tillers starts from the analysis of simpler inferences to successively show the reader how it is easy to get to situations where the visual representation in legal matters grows very complex, so that to handle them without an adequate system of representation becomes impossible. Prof. Tillers finally argues that in order to make useful graphical representations of inferences in the legal field, as well as an appropriate notation, they should be structured in the same way that our mind organizes our thoughts, in order that the graphical representation improve heuristic analysis of the available material.

Keywords: representation of factual inferences.

* Me gustaría agradecer a la Facultad de Derecho de la Universidad de Seattle el futuro apoyo que me va a prestar, apoyo que posibilita que el presente trabajo salga a la luz. Una primera versión del mismo fue realizada como conferencia para la Facultad de Derecho de la Universidad de Sichuan el 6 de abril de 2004. Agradezco igualmente la hospitalidad y comentarios de mis anfitriones en dicha Universidad. Me gustaría agradecer también a la Facultad de Derecho Cardozo su apoyo en mi visita a China. Por último, me gustaría mostrar mi agradecimiento a David KAYE por sus comentarios a mi conferencia en China. 
«El tiempo es la forma que tiene la naturaleza de impedir a la gente pensar en todo al mismo tiempo»

ANÓNIMO

\section{INTRODUCCIÓN}

\subsection{Imágenes frente a palabras}

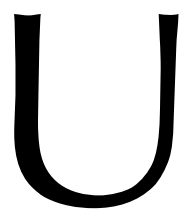

$\mathrm{n}$ viejo refrán dice que una imagen vale más que mil palabras. No creo sin embargo que dicha afirmación pueda predicarse de todas las imágenes. De hecho, en lo que aquí nos ocupa, hace ya tiempo que se intenta utilizar imágenes (diagramas) que permitan describir la inferencia y la prueba en el ámbito jurídico con un éxito más bien escaso -alguno de dichos intentos ha sido de hecho un espectacular fracaso según veremos más adelante.

El presente trabajo plantea el papel que puede representar la visualización de los problemas de la evidencia ${ }^{1} \mathrm{y}$ de la inferencia desde un punto de vista diferente respecto del cual hasta ahora se había efectuado. Se parte aquí de la suposición de que, para que el uso de representaciones — gráficos, diagramas y cuadros_ pueda facilitar la inferencia de hechos y, en definitiva, la actividad probatoria en el ámbito jurídico, las mismas deben ser expresadas de la misma forma que el cerebro obtiene y organiza su conocimiento de la realidad.

También se parte de la afirmación de que la inferencia tiene, en la práctica jurídica, cuatro características generales importantes: $1 .^{\circ}$ la complejidad y lo intrincado de las pruebas reunidas y ordenadas; $2{ }^{\circ}$ la diversidad de los métodos para organizar la prueba; $3 .^{\circ}$ la influencia del tiempo y de los cambios en la inferencia, y; finalmente, $4 .^{\circ}$ el papel que la imaginación y la invención «heurística - tienen en la inferencia de hechos.

Este trabajo pretende demostrar que estas cuatro características sirven de apoyo a la idea de que los procedimientos informatizados de visualización de las cuestiones que plantea de la evidencia y la inferencia pueden ser más útiles y eficientes si: $1 .^{\circ}$ por un lado, mejoran la capacidad de los participantes en procesos jurídicos (reales o potenciales) de cambiar rápidamente entre la perspectiva global, o sintética, y granular, o analítica, en relación con la evidencia y con los diversos métodos de organizar la misma, y;

${ }^{1}$ N. del T.: La palabra «evidence» se puede traducir en el ámbito del Derecho procesal como «medio de prueba», «indicio» o más simplemente «prueba», ya que en la práctica se utilizan dichos términos de forma sinónima (aunque el último debería emplearse sólo para aquello que es objeto de prueba o el resultado de la práctica de la prueba). En la traducción, sin embargo, se empleará con carácter general el término «evidencia», que en español tiene un significado similar a «evidence» y se puede utilizar en cualquier contexto, lo mismo que en inglés, pues si bien no es una expresión habitual en el ámbito jurídico, lo cierto es que su campo semántico es más amplio que el de la expresión «medio de prueba», que sólo se emplea en el estrecho marco de los procesos judiciales (en el proceso penal se utiliza también el término «indicio»). Por su parte, la expresión «prueba» la reservo en general para la traducción de «proof» que vendría a ser «prueba efectiva», expresión esta última que sin embargo en español no se utiliza. No obstante, en ocasiones se utilizarán otros términos para traducir «evidence», tales como: hecho, indicio, medio de prueba e, incluso, pruebas, según el contexto, ya que como criterio general cuando se ha tenido que elegir entre ser coherente y ser claro se ha preferido en aras a la mejor comprensión del texto modificar los términos de la traducción (tradutore traditore). 
2. ${ }^{\circ}$ por otro lado, permite tener a la vista, tanto en los aspectos de fondo cuanto en los marginales, aquel conjunto de pruebas que no son el foco de la atención de ese participante mientras se halla concentrado en otro conjunto de evidencias. Hay razones para creer que es precisamente la, hasta la fecha, carencia de métodos de visualización que, de un lado, dispongan de varias capas de análisis y, de otro, que permitan examinar los problemas de la evidencia y de la inferencia de forma flexible, el motivo por el cual muchas de las fórmulas que se han propuesto para representar el proceso probatorio y los argumentos sobre el mismo, apenas tengan de interés para los potenciales usuarios y, consecuentemente, hayan devenido inútiles.

\section{NORMAS, PRUEBA, Y EVIDENCIA}

\subsection{Las normas como imperativos condicionales ${ }^{2}$ y autorizaciones condicionales, y la importancia de la prueba de los hechos}

La mayoría de las normas son o imperativos condicionales o permisos condicionales. Del mismo modo, muchas normas contienen mandatos legales condicionales o autorizaciones condicionales. Las condiciones que encontramos en tales normas (condicionales), se refieren generalmente a posibles condiciones o situaciones de la realidad o a posibles sucesos de esa misma realidad. De las normas condicionales, por otra parte, procede la autoridad que permite aplicar la correspondiente consecuencia jurídica que, en cualquier caso, depende de que se constate la existencia o no de los supuestos de hecho que conforman los tipos concretos de acontecimientos de tal realidad. La existencia de imperativos y autorizaciones condicionales de carácter jurídico es una de las razones fundamentales de la importancia de la prueba de los hechos y de la proposición de prueba en los procedimientos judiciales, pues la función primaria - y quizá principal— de la proposición de prueba en tales procedimientos, es establecer una determinación vinculante en relación con la cuestión relativa a si existen los supuestos de hecho que conforman los tipos de sucesos o circunstancias que se han de constatar para la aplicación de la consecuencia jurídica ( $v$. gr. la pena en los delitos, la validez de un negocio jurídico).

\subsection{Relaciones entre la evidencia y la prueba de los hechos}

Existe en la comunidad jurídica de los Estados Unidos - y probablemente en la mayor parte del mundo- un consenso relativo a que los procedimientos legales, especialmente en juicios en que se debaten cuestiones de hecho, deben resolverse por medio de pruebas mejor que por medio de ordalías, $v$. $g r$. se está en general de acuerdo, afirmándolo negativamente, que no hay ontología conocida que establezca que algo o alguien en el cielo pueda proporcionar respuestas fiables a las preguntas acerca de la certeza de los hechos.

${ }^{2} N$. del T.: En español jurídico usualmente se utiliza la expresión «imperativo hipotético» siguiendo una tradición neokantiana, pero la expresión utilizada también es admisible (vid. FERRATER MORA, Diccionario de Filosofía, voz «Imperativo») y es más fiel al original. 


\section{LA INCERTIDUMBRE DE LA INFERENCIA Y EL LENGUAJE}

\subsection{La incertidumbre de la inferencia de hechos y de la prueba de hechos}

El Derecho probatorio [law of evidence ${ }^{3}$ americano descansa sobre el presupuesto de que la prueba nunca o raramente establece de forma concluyente que un suceso o sucesos se produjeron o no, y que la prueba raramente, si alguna vez lo hace realmente, establece que sea cierto que un suceso concreto haya tenido existencia real, ocurriese o no en la realidad.

\subsection{El lenguaje y la notación para hablar acerca de la inferencia de hechos sobre los que no existe certidumbre}

Hay varias maneras formalmente equivalentes de hablar sobre la inferencia de hechos sobre los que no existe certidumbre. Un tipo de discurso hace uso de la siguiente notación:

$\mathrm{H}=$ hipótesis sobre un hecho

$\mathrm{E}=$ evidencia

I = dado, asumiendo que

Visto de esta forma, la proposición de la prueba en los procedimientos legales hace posible para el que tiene que valorar la prueba —el «juzgador de hechos»—- hacer un juicio sobre:

$\mathrm{H} \mid \mathrm{E}$

V. gr. la hipótesis del hecho $H$ dada la evidencia $E$.

\subsection{Nomenclatura y notación para el enlace entre las evidencias y las hipótesis: denotando y representando la inferencia}

Pensamos que la relación entre una hipótesis sobre un hecho $H$ y una evidencia $E$ envuelve un posible paso de $E$ a $H$. Hay muchas maneras de enfatizar la existencia de tal posible paso desde la evidencia hasta la hipótesis sobre un hecho. Una de las formas de hacerlo, es la clase de gráfico que se muestra como Figura 1:

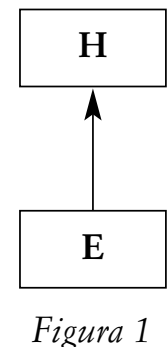

${ }^{3}$ En buena parte del mundo, las normas que regulan el uso de los medios de prueba en los procedimientos judiciales se denominan «Derecho de prueba» (law of proof) en lugar de «Derecho de las pruebas» (law of evidence). En este trabajo se utilizarán ambas locuciones en forma indiferente. 
La conexión entre $H$ y $E$ puede ser también dibujada en la forma que se muestra en la Expresión 1:

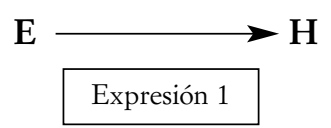

En cualquier caso - cualquiera que sea la manera que elijamos para describir el enlace entre $E$ y $H$ - en el mundo de habla inglesa el paso que va desde $E$ hasta $H$ se denomina convencionalmente $\ll$ inferencia» ${ }^{4,5}$.

\subsection{Inferencia, incertidumbre y teoría de la probabilidad}

Es casi imposible hablar de la inferencia de hechos sin tener en cuenta la teoría de la probabilidad. Si creemos que la prueba de los hechos implica más la incertidumbre que la certidumbre de la inferencia, es normal pensar que la teoría de la probabilidad puede jugar un importante papel para la prueba de los hechos y para el dominio de la técnica de los procedimientos probatorios en los procesos legales. De hecho, la siguiente clase de expresiones en términos de probabilidad estándar puede ser correctamente interpretada como una reafirmación de los dos conceptos principales que este trabajo ha discutido hasta este momento:

\section{$\mathbf{P}(\mathrm{H} \mid \mathrm{E})$}

\section{Expresión 2}

En esta expresión (como antes)

$H=$ hipótesis de hecho

$E=$ evidencia

I = dado

El nuevo símbolo aquí es:

$P=$ probabilidad

Las expresiones de la forma $P(H \mid E)$ expresan, valga la redundancia, probabilidad condicionada. Desde el punto de vista de la teoría de la probabilidad, un juicio acerca

${ }^{4}$ La connotación ordinaria de la palabra alemana «Folgerung» difiere de la connotación ordinaria de la palabra inglesa «inference». «Folgerung» encaja mejor con la palabra inglesa «deduction». La palabra inglesa «inference» a menudo denota y connota una inferencia sobre la que no existe certidumbre.

${ }^{5}$ N. de T.: El DRAE define inferencia como «acción de inferir», e inferir como «sacar una consecuencia o deducir algo de otra cosa», que en mi opinión es un significado muy similar al que la palabra «inference» tiene en habla inglesa, toda vez que se diferencia de la «deducción» (acción de deducir) en que ésta consiste en «sacar consecuencias de un principio, proposición o supuesto» (DRAE), lo que lleva a que también en español la inferencia denota una cierta incertidumbre (a diferencia de la deducción) y, consecuentemente, que la correspondencia entre la palabra inglesa y la española sea bastante precisa. 
de la relación entre $E$ y $H$ es un juicio acerca de una probabilidad condicional. Esto significa que desde el punto de vista de la referida teoría una inferencia a partir de una evidencia es un juicio sobre la probabilidad de una hipótesis como $H$ dada alguna otra proposición, suceso o evidencia como puede ser $E$. Por tanto, la probabilidad $P$ de la hipótesis o proposición $H$ dada $E$, expresa el grado de incertidumbre de la proposición $H$ dada la proposición, premisa, suceso o evidencia $E$.

La teoría de la probabilidad —en particular en su rama bayesiana ${ }^{6}$ - proporciona un poderoso instrumento para el estudio de la inferencia de hechos sobre los que no existe certidumbre y la prueba de hechos en asuntos judiciales y procedimientos. Este trabajo, en cualquier caso, no trata (al menos no directamente) de la relación existente entre la teoría de las probabilidades y la inferencia de hechos sobre los que no hay certidumbre o la prueba de hechos no concluyentes en el ámbito jurídico. La tarea de este trabajo es paralela a la de la teoría de la probabilidad.

\section{REPRESENTANDO INFERENCIAS SIMPLES Y COMPLEJAS}

\subsection{Representando inferencias simples}

En este apartado sugiero que hay razones para sospechar o creer que la representación gráfica y visual de la prueba de los hechos en los procedimientos judiciales puede ser útil para, al menos, algunos de los participantes en el proceso. La exposición efectuada hasta ahora, sin embargo, no parece que sugiera la imperiosa necesidad de la representación visual o gráfica de la inferencia de hechos. Expresiones tales como la Expresión 3:

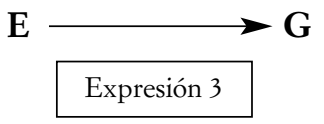

Parecen perfectamente inteligibles. De hecho, con inferencias de esta simplicidad quizá pudiésemos incluso dispensar la utilización de la notación simbólica. Supongamos que $E$ representa «el acusado escapó de la prisión» y $G$ «la culpabilidad penal del acusado» ${ }^{7}$. ¿Ganamos algo diciendo o escribiendo $E \rightarrow G$ ? Parece que podemos en-

${ }^{6}$ N. de T.: Para los no familiarizados con esta terminología, se entiende por probabilidad «bayesiana» aquella que tiene su base (o más bien su origen) en el trabajo del Rev. BAYES sobre el cálculo de la probabilidad de un suceso «An Essay towards solving a Problem in the Doctrine of Chances» (se pueden encontrar en el libro Evidence, Proof, and Facts. A book of Sources, de P. MuRPHY, pp. 438 a 457), aunque también es habitual denominarla probabilidad pascaliana. Las alternativas, si mi información no es incorrecta, son, de un lado, la probabilidad inductiva o baconiana (vid. CoHEN, 1977: The probable and the provable, Oxford, pp. 121 y ss., que en buena parte se encuentra traducido en el libro de AISA MOREU, El razonamiento inductivo en la ciencia y en la prueba judicial, pp. 261 a 371), y, de otro, las funciones de credibilidad de SHAFER (1976: A Mathematical Theory of Evidence, Princeton University Press). Una buena exposición de todo ello se encuentra en ScHum, 2001: The Evidential Foundations of Probabilistic Reasoning, Northwestern University Press, un bayesiano bastante convincente.

${ }^{7}$ N. de T.: Recuérdese que «culpabilidad» o «culpa» en inglés es «guilt» $(\mathrm{G})$. 
tender perfectamente las proposiciones del tipo que a continuación mostramos incluso si las mismas se expresan en lenguaje ordinario:

i) Dada la evidencia de que el acusado escapó de prisión, la culpabilidad penal del mismo es posible.

ii) Dada la evidencia de que el acusado escapó de prisión, de ello infiero que el acusado es culpable.

De hecho, a menudo el uso de la notación simbólica conlleva el riesgo de que se enmascaren las ambigüedades e incertidumbres que inmediatamente aparecen cuando se usa el lenguaje común (tal como el usado ut supra).

No obstante, sería prematuro concluir que las representaciones visuales y gráficas de los problemas de la inferencia de hechos son inútiles. Antes debemos considerar el hecho de que la inferencia, a menudo, es más compleja de lo que hasta ahora se ha expuesto.

\subsection{Inferencias complejas}

Las inferencias «simples» incluyen una única hipótesis (fáctica) tal como $H$ y una única premisa (evidencia) tal como E. Las inferencias «complejas» por el contrario implican más de una inferencia.

Un ejemplo judicial habitual de inferencia compleja lo constituye la cuestión de la probabilidad de la posible culpa $G$ de un acusado dada la evidencia $E$ de que el acusado escapó de prisión. ¿Son las expresiones como la Expresión 3 suficientes para describir la cuestión o cuestiones que están en disputa cuando una evidencia tal que $E$ es tomada en consideración? Muchos estudiosos del Derecho piensan que no, piensan que la Expresión 3 debe ser ampliada hasta alcanzar al menos dos inferencias como en la Expresión 4:

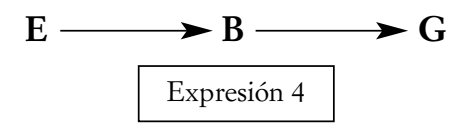

$E=$ fuga (escape)
$B=$ creencia (belief) del acusado en su culpabilidad
$G=$ culpabilidad (guilt)

\subsection{Inferencias más complejas. Ramificando la inferencia}

La existencia de inferencias complejas —inferencias que contienen más de un único paso inferencial - crean la posibilidad de ramificar la inferencia. Nada en la lógica impone que la inferencia en una red de inferencias tenga que tener siempre la forma de una única cadena. Nada en la lógica impone tampoco que una premisa fáctica deba servir para sustentar una única inferencia. La ramificación de las inferencias es en consecuencia posible. 
En ocasiones, por otra parte, ramificar enlaces (o ramificar series de enlaces) parece obligado. Por ejemplo, el problema que conlleva la fuga de $E$ comienza con una cadena sencilla ( $v i d$. Expresión 1). La inferencia simple adopta siempre la forma de una cadena única. En ocasiones, sin embargo, el problema permanece en la forma de una simple cadena aun cuando el problema se vuelve más complejo (vid. Expresión 4). Pero supongamos que (i) el imputado, el fugado, va a ser juzgado por robo y es posible que, en el momento de la fuga, (ii) crea que es culpable de robo y (iii) crea que es igualmente culpable de asesinato. En esta situación es igualmente probable que la Expresión 4 no llegue a describir el problema de la evidencia y la inferencia muy bien. En este sentido, el gráfico de la Figura 2 es una representación del problema más adecuada — porque el gráfico de la Figura 2 tiene dos cadenas con origen en una única premisa fáctica $E$ : a diferencia de la Expresión 4, el gráfico de la Figura 2 deja claro que la fuga $E$ del imputado sirve de sustento a dos series alternativas de inferencias, una que se dirige hacia la inferencia de robo (robbery), y otra, hacia la inferencia de asesinato (murder).

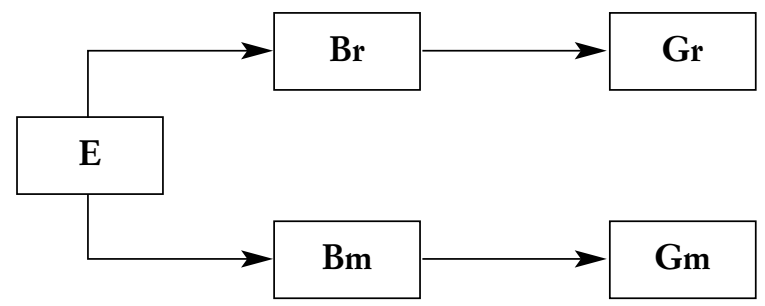

$B_{r}=$ creencia (belief) del imputado en su culpabilidad por robo (robbery)

$G_{r}=$ culpabilidad (guilt) del imputado por robo (robbery)

$B_{m}=$ creencia (belief) del imputado en su culpabilidad por asesinato (murder)

$G_{m}=$ culpabilidad (guilt) del imputado por asesinato (murder)

Figura 2

\subsection{Otra causa de la complejidad de la inferencia: La incertidumbre en la fuente}

Junto a su capacidad de hacer brotar ramas, las cadenas de inferencias tienen la capacidad para hacerse más largas. Es más, en algunos casos deben crecer más si se quiere representar adecuadamente los problemas de la evidencia y la inferencia. Por ejemplo, la cadena de inferencias abierta en la Figura 2 debe crecer si no existe certeza sobre la premisa fáctica de la cadena - la proposición representada por el símbolo E- La ampliación que muestra la Figura 3 es necesaria si existe incertidumbre sobre la premisa $E$ y descansa en una declaración testifical (testimonial report) no concluyente, siempre que el resto de los pasos del complejo de inferencias permanezca igual. 


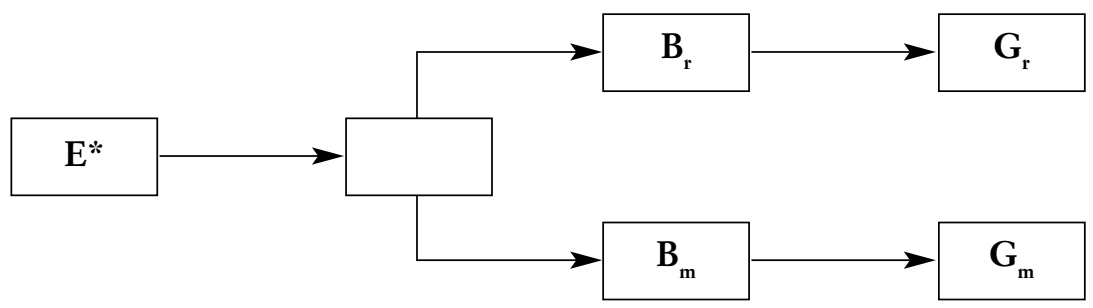

$E^{*}=$ declaración testifical del suceso $E$ (escape)

$E=$ suceso $E$ (escape)

$B_{r}=$ creencia (belief) del imputado en su culpabilidad por robo (robbery)

$G_{r}=$ culpabilidad (guilt) del imputado por robo (robbery)

$B_{m}^{r}=$ creencia (belief) del imputado en su culpabilidad por asesinato (murder)

$G_{m}^{m}=$ culpabilidad (guilt) del imputado por asesinato (murder)

Figura 3

\subsection{Otra fuente de complejidad de la inferencia: La expansión de la cadena de inferencia por descomposición}

En la medida que voy usándola, la complejidad de la inferencia se encuentra determinada enteramente por el número de inferencias de una red de inferencias. Sin embargo, el número de inferencias de un problema depende en gran parte del punto de vista del observador. Como la percepción del observador se va refinando progresivamente - a medida que el observador de un problema disecciona el problema de la prueba en más partes-, el número de inferencias posibles en un complejo de inferencias puede multiplicarse. Por ejemplo, el observador puede concluir que un enlace en concreto de la cadena o red de inferencias en realidad debe contener varios enlaces en lugar de uno solo.

Consideremos la cadena de inferencias que ha evolucionado en la red que tenemos en la Figura 3. Esta red puede ser desgranada y, por tanto, ampliada. Supongamos que el observador de la declaración testimonial $E^{*}$ cree (como el Derecho americano supone) que los juicios de credibilidad de un testigo no son juicios primarios o irreducibles, sino que son juicios compuestos basados en juicios parciales sobre varios atributos del sujeto del que proceden, que parecen constituir las declaraciones del tipo de $E^{*}$. Supongamos en concreto que el observador del problema cree que el juicio compuesto sobre la creencia, o credibilidad, de tal clase de declaraciones depende de juicios sobre los siguientes atributos del sujeto del que proceden:

$N$, la capacidad del testigo de comunicar;

$V$, la buena voluntad de una persona al afirmar lo que cree que es verdad;

$O$, el grado de objetividad de un testigo y, por tanto, la capacidad de la persona de interpretar objetivamente las señales sensoriales que sus sentidos le transmiten;

$M$, la capacidad de una persona de retener en la memoria (en el cerebro) el recuerdo original que dejaron las señales sensoriales que sus sentidos le enviaron; y, finalmente, 
$S$, la capacidad de los órganos sensoriales del testigo para recibir correctamente las señales que el entorno envía a dichos órganos.

Si el observador, o el analista, cree que las inferencias y juicios sobre cada uno de estos atributos personales — «cualidades del testigo» («testimonial qualities»)— son necesarios para determinar la credibilidad de una declaración testifical, este analista — -si quiere usar representaciones de la clase que aquí analizamos y si quiere que tales representaciones sean adecuadas al problema al que tiene que enfrentarse- debe, en el caso del problema de la evidencia de la fuga, ampliar el gráfico de la Figura 3 de tal manera que el mismo tenga enlaces adicionales, o inferencias, que encontramos en la red que muestra la Figura 4.

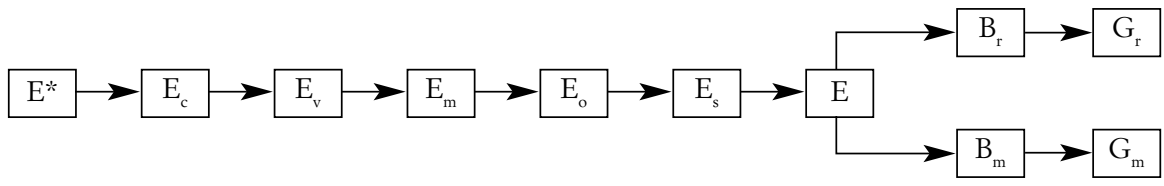

$E_{c}=$ si la fuente (el testigo que declara) de $E^{*}$ declara lo que él quiere decir

$E_{v}^{c}=$ si la fuente afirma lo que él cree que es verdad

$E_{m}=$ si la fuente ahora piensa lo que él originalmente pensó de datos que le proporcionaron los sentidos

$E_{o}^{m}=$ si la interpretación de la fuente de señales sensoriales es imparcial

$E_{s}^{o}=$ si los órganos sensoriales de la fuente recogen con precisión los estímulos que reciben sus sentidos

Figura 4

\subsection{Otras formas de complejidad en la inferencia: Proposiciones subordinadas y evidencia subordinada}

Una serie de inferencias de la clase de las que encontramos en la Figura 4 puede ser aún más compleja —y adquirir una estructura más compleja todavía— si añadimos proposiciones subordinadas. Una proposición subordinada es una proposición que puede ayudar a sostener una posible inferencia en la serie, cadena, red o malla de inferencias principales. Si un conjunto de posibles inferencias forma una escala y cada posible inferencia es un escalón de la misma, las proposiciones subordinadas son los asideros adyacentes a cada escalón que proporcionan el soporte necesario para el ascenso de un escalón al siguiente ${ }^{8}$.

Las proposiciones subordinadas pueden asociarse con cualquier paso de la cadena. Pueden también ser asociadas con juicios concretos sobre los atributos de una testifical — tales como veracidad, sensibilidad de los sentidos, etc.— que sean pertinentes

${ }^{8}$ La metáfora de la escala no es perfecta. Por ejemplo, cuando se sube una escala de inferencias, uno no puede mejorar su situación en la escala saltando a escalones que uno todavía no ha alcanzado. En este sentido, subir una escala de inferencias es, probablemente, más parecido a subir la pared vertical de una montaña mediante el procedimiento de ir picando una serie de agujeros en la pared vertical para afianzar el pie a cada paso. 
para un juicio de conjunto, o una inferencia, acerca de la credibilidad de un testigo. Consideremos una vez más el problema hipotético que envuelve la declaración $E^{*}$ de la fuga $E$. En dicha situación uno podría correctamente desear tomar en consideración una proposición como $D$, «Una persona con degeneración grave de la mácula del ojo normalmente no puede percibir o procesar estímulos visuales que sean indicativos de las características del rostro de una persona a una distancia de 30 metros». Si esta proposición subordinada se añade al dibujo de la posible inferencia que tenemos, el argumento basado en la evidencia $E^{*}$ puede ahora tener el aspecto de la Figura 5.

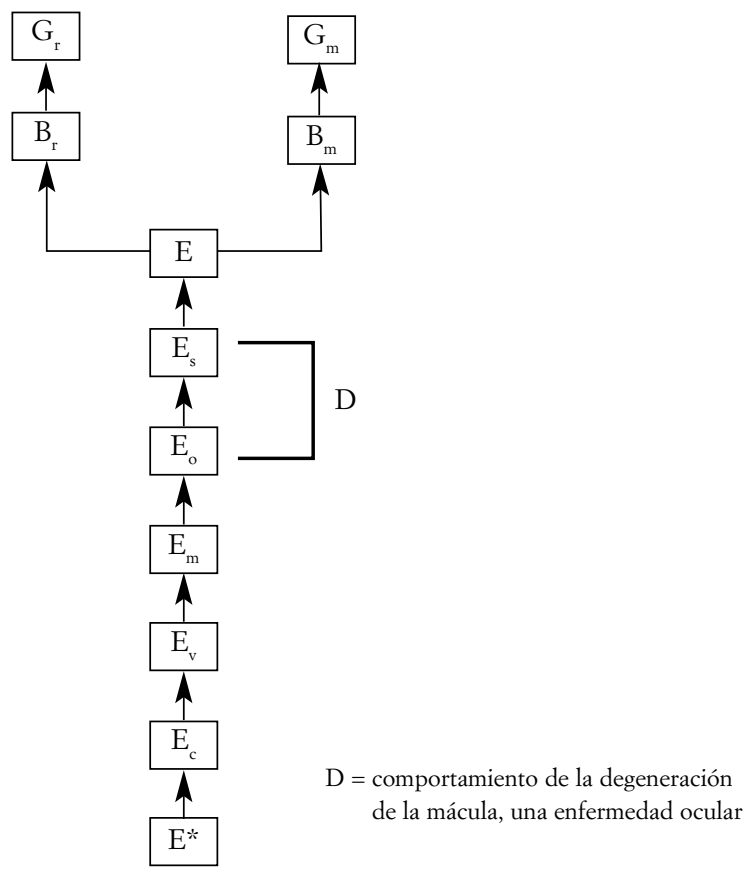

Figura 5

El complejo 9 de inferencias que muestra la Figura 5 llega a ser más intrincado si la evidencia acerca de posibles proposiciones subordinadas como $D$ son tenidas en consideración. Por ejemplo, la persona que hace juicios acerca de la capacidad del testigo para percibir con sus ojos, puede apoyarse en un manual sobre enfermedades y en unos

${ }^{9}$ Deliberadamente uso la polisémica palabra «complejo» («complex») en lugar de la más concreta «red» («network»). En la teoría de los gráficos los nodos pertenecen a la misma red (network) sólo si se encuentran enlazados directa o indirectamente por flechas. En el esquema que yo uso, las proposiciones subordinadas (y la evidencia subordinada a la que se encuentra enlazada) no se encuentra enlazada a los nodos de la red de inferencias primaria; las proposiciones subordinadas y la evidencia subordinada que las soporta no se encuentran directamente enlazadas a la red de inferencias principal a la que rodean y sostienen (este criterio no carece de controversia, pero es común, especialmente entre analistas jurídicos de la estructura de la inferencia). 
pocos artículos de periódico sobre la degeneración de la mácula del ojo o, finalmente, en conversaciones con gente experimentada que le expliquen el significado de sus conversaciones con los oftalmólogos. Un ejemplo de un diagrama que tome en consideración tales evidencias subordinadas aparece en la Figura 6.

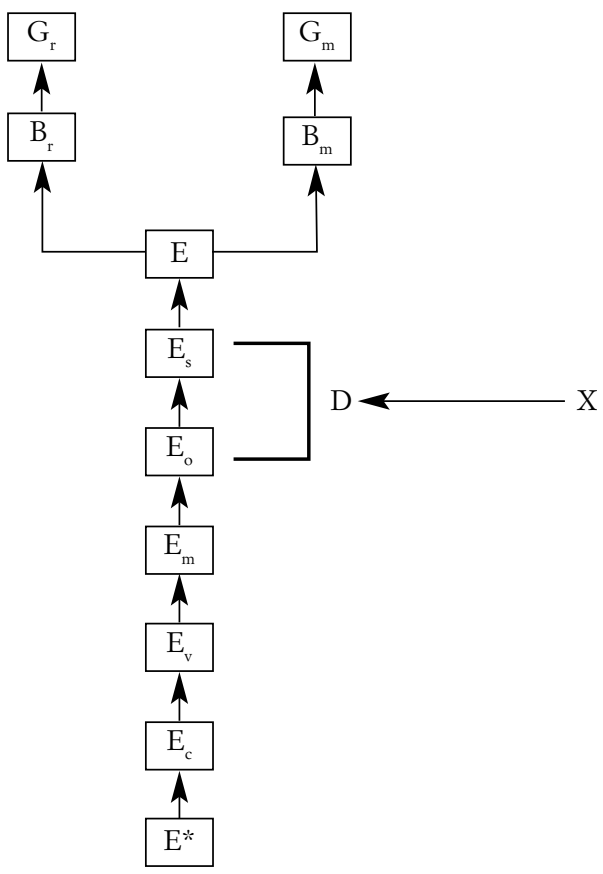

Figura 6

Sería tedioso, e innecesario, demostrar mediante ejemplos específicos que la elaboración de redes de inferencia subordinadas puede generar complejidad adicional de carácter sustantivo e intrincabilidad en los complejos de inferencia relacionados. Baste decir que las redes de inferencias subordinadas pueden incrementar la complejidad de las ya complejas inferencias en alguna o alguna de las siguientes formas:

i) cada enlace de la cadena principal de inferencias puede asociarse con múltiples proposiciones subordinadas y no sólo con una ${ }^{10}$,

ii) Cualquier proposición subordinada puede ser asociada a varios elementos de prue$\mathrm{ba}-\mathrm{o}$ incluso a un importante conjunto de evidencia subordinada - y no sólo a uno ${ }^{11}$, y

${ }^{10}$ Por ejemplo, en la cadena mostrada en la Figura 6, una proposición o proposiciones sobre otra enfermedad ocular o daño ocular puede ser pertinente para juzgar acerca de la sensibilidad de los sentidos del testigo que hace la declaración $E^{*}$.

11 Por ejemplo, prácticamente existe la certeza de que, en el caso, una gran cantidad de evidencia científica puede servir como base para cualquier proposición subordinada acerca de las características de la degeneración de la mácula. 
iii) El enlace entre las proposiciones subordinadas y las evidencias que sostienen dichas proposiciones puede ser indirecto más que directo, pues la senda entre la evidencia y las proposiciones subordinadas puede tener (y frecuentemente así sucede) la misma clase de estructura de escala o malla que la red de inferencias principales normalmente tiene.

\subsection{Sopesando los costes y beneficios de la visualización de la inferencia compleja}

Algunas de las concretas redes de inferencias y diagramas de inferencia que hemos analizado pueden parecer complejos, y, por supuesto, hay un cierto sentido en el que las clases de redes y diagramas de inferencias que hemos estado analizando son de hecho complejos: pueden contener numerosos nodos y, por tanto, numerosas proposiciones. Pero en otro sentido, los tipos de redes complejas y diagramas complejos que hemos estado analizando hasta ahora son relativamente simples.

La complejidad de las redes y diagramas que se han analizado es atribuible casi por entero al número de nodos - $\mathrm{y}$, por tanto, de proposiciones- que tienen estas redes y diagramas. Una red o diagrama de inferencias que es complejo por este motivo puede, por supuesto, consumir una gran cantidad de tiempo y recursos del usuario o del diseñador del mismo. Pero cuando la complejidad se deriva principalmente del número de proposiciones en un complejo de inferencias, se puede sostener que no es difícil. Ello se debe a que cuando la complejidad se debe únicamente al número de posibles inferencias en una serie de inferencias hay una relativamente simple y eficaz estrategia para abordar el problema: la estrategia para abordar cadenas de inferencias simples con numerosos nodos es dividir y conquistar. Comenzando por el principio, consideremos cada inferencia posible en orden; hagamos un juicio acerca de cada posible inferencia; vayamos entonces a la siguiente inferencia de la serie de inferencias y repitamos el proce$\mathrm{so}^{12}$. Afirmando, por el contrario, que la estrategia adecuada consiste en lo siguiente: i) trabajar en la escala de inferencias sobre un solo escalón cada vez; y, ii) cuando se tenga un nuevo punto de apoyo en la escala, se deja atrás la parte de la escala en la que se había estado con anterioridad.

La estrategia de dividir y conquistar —o estrategia de un paso cada vez- es relativamente sencilla y utilizándola es relativamente fácil mantener las exigencias de tal

${ }^{12}$ Mi sugerencia de una estrategia de dividir y conquistar no es una tentativa por mi parte de unirme a una discusión ya iniciada entre teóricos de la probabilidad, científicos informáticos y otros estudiosos sobre técnicas para mejorar el manejo de redes de inferencia complejas. Los motivos por los que las redes de inferencias se encuentran bajo discusión en estos círculos — fundamentalmente redes de Bayes - es facilitar el cálculo de probabilidades condicionales dependientes; el motivo de la discusión en estos círculos es diseñar estrategias que eviten la formación de redes de inferencias que generen demandas de cálculo que sean, bajo ciertos estándares, excesivas. Mi objetivo en el estudio de las redes de inferencia no es descubrir métodos de análisis o cálculo que puedan imitar o reemplazar las operaciones de inferencia originales del cerebro humano, como tampoco lo es, ni mucho menos, el desarrollo de procedimientos para la valoración automatizada de las incertidumbres inferenciales. Este trabajo, en su lugar, asume que el cerebro humano de alguna manera se las arregla para desarrollar complejos cálculos inferenciales y, por tanto, tiene por objeto sólo una cuestión: ¿Qué clase de representaciones visuales (si las hay) —o qué clase de instrumentos— pueden ayudar al cerebro humano (o al organismo humano) a desarrollar la compleja actividad inferencial un poco mejor de lo que lo hace actualmente? 
proceder en mente. La estrategia de dividir y conquistar a la hora de construir una serie de inferencias tiene la ventaja adicional de permitir que los pasos terminados sean excluidos del pensamiento una vez que la inferencia ha sido considerada y valorada, sólo se precisa tener en consideración la línea base o línea principal, y una vez la siguiente posible inferencia de una serie ha sido determinada, nuevamente sólo debemos tener en mente la línea base o principal. Este rasgo de la estrategia de dividir y conquistar —o estrategia de subir la escala de inferencias escalón a escalón, dejando los escalones subidos previamente atrás y fuera del pensamiento- sugiere que las ventajas de visualizar los problemas de las inferencias complejas pueden no ser tantas como podíamos imaginar. Quizá los seres humanos puedan dirigirse — paso a paso— a través de «complejos» problemas de evidencia e inferencia sin el soporte de ayudas como gráficos, cuadros y diagramas. Y si estas ayudas se necesitan para trabajar a través de una larga serie de inferencias, quizá una lista escrita a mano de la serie de inferencias podría considerarse suficiente.

Un observador amistoso podría precipitarse en la defensa de los postulantes de la visualización y decir:

Esto es ridículo. La representación visual de los problemas de evidencia e inferencia no son una varita mágica, es evidente que no resolverá todos los problemas, y quizá podamos pasar sin ella. Pero los cuadros, diagramas y gráficos sin duda son útiles en algún grado. Realmente no hay debate. ¡Visualicemos!

Pero por mucho que me gustase seguir el consejo de tan amable observador, no puedo. La defensa de la visualización que hace mi hipotético observador se basa en la presunción de que la visualización no tiene costes. Esta presunción, sin embargo, carece de fundamento.

El uso de técnicas de visualización del pensamiento para describir la inferencia de hechos efectuada a la sombra de la ley conlleva un precio exacto - y dicho precio en el caso de algunas técnicas de visualización de los problemas de evidencia puede ser muy gravoso- - Por ejemplo, algunos de los métodos de visualización de problemas de inferencia propuestos hacen uso de una gramática «antinatural», entendiendo por tal la que no es a priori familiar a los usuarios potenciales y requiere una considerable inversión de tiempo para el dominio de dichos tipos de representaciones visuales ${ }^{13}$. Además, es posible, e incluso probable, que la utilización de algunas de las técnicas para construir los gráficos visuales de los problemas de evidencia e inferencia demande inversiones sustantivas de tiempo y recursos incluso después de que se haya alcanzado a dominar la gramática de un método concreto de representación visual.

La experiencia histórica sugiere que es juicioso ser cauto a la hora de inflar las demandas y expectativas sobre los beneficios que puede traer la visualización de los problemas de evidencia e inferencia. El esfuerzo realizado por el más eminente de los estudiosos americanos de la técnica de la visualización del pensamiento, John Henry WigmORE, constituyó un espectacular fracaso. Él dibujó diagramas como el de la Figura 7.

${ }^{13}$ Nadie debería asumir gratuitamente que el uso de visualización llegará a compensar en coste el lenguaje y discurso ordinarios (no visuales). 
$\$ 33$. Same: an Example Charted. We shall thus have carted the results of our reasoning upon the evidence affecting any single probandum. But this probantum will usually nowin its turn (ante, $\$ 8$ ) become an evideniary fact, towards another probantum in a catenate inference. The process of charting and valuation has then to be renewed for this new pronantum; and so on until all the evidence has been charted, and the ultimate probanda in issue under the pleadings have been reached.

The following portion of a chart will illustrate (taken from the case of Com. v. Umilian, post, $\$ 38)$ :

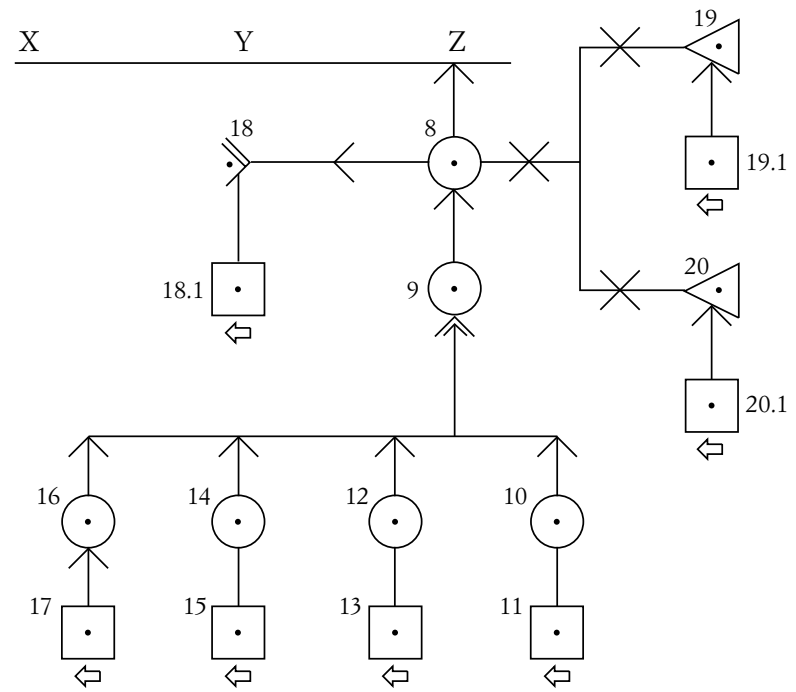

$\mathrm{Z}$ is one of the ultimate probanda under the pleadings, viz. that the accused killed the deceased. Cirle 8 is one of the evidentiary facts, viz., a revengeful murderous emotion. The arrowhead on the line from 8 to $\mathrm{Z}$ signifies provisional force given to the inference.

Fuente: J. H. Wigmore, Principles of judicial proof (1. ${ }^{a}$ ed., 1917). Vid. también J. H. WigmoRE, The science of judicial proof as given by Logic, Psycology, and General experience and ilustrated in judicial trials (3. ${ }^{a}$ ed., 1937).

\section{Figura 7}

WigmORE obligaba a sus estudiantes a hacer gráficos con los problemas de evidencia. Wigmore también intentó que los abogados usasen sus métodos de análisis de la prueba mediante gráficos, pero no tuvo éxito en este ámbito. Tras la muerte de WigMO$\mathrm{RE}$, por otra parte, ningún estudiante se tomó la molestia de usar el método de análisis mediante gráficos de WigMORE. En resumen, el método de análisis de la evidencia y la inferencia mediante gráficos (method of charting) se hundió como una bola de plomo ${ }^{14,15}$.

${ }_{14}$ TwINING, 1985: Theories of Evidence: Bentham and Wigmore, Stanford U. Press.

${ }^{15} \mathrm{~N}$. de T.: No quisiera que la referida crítica hiciese que los lectores de habla hispana se llevaran una impresión errónea acerca de WIGMORE, que sin duda es el autor más importante de habla inglesa junto a BENTHAM y quizá THAYER en la materia. 
Es posible que el proyecto de grafiar la evidencia y los argumentos relativos a la evidencia estén condenados al fracaso. Es también posible, sin embargo, que haya una explicación diferente para el fracaso de WIGMORE: es posible que los gráficos de WIGMORE fracasaran porque eran confusos y estaban mal diseñados; es posible finalmente que los esfuerzos de WIGMORE se hundieran porque sus diagramas eran malas representaciones $^{16}$. Quizá la cuestión importante no es si las imágenes, gráficos, cuadros y diagramas pueden ser útiles, sino qué clase de imágenes o diagramas lo son.

Pero si aceptamos esta hipótesis, nos enfrentamos a una cuestión realmente difícil ${ }^{17}$ : ¿Qué clases concretas de imágenes, diagramas, gráficos y cuadros pueden probar su utilidad a los participantes en la actividad inferencial que se lleva a cabo en la trastienda de los procedimientos judiciales hipotéticos o reales?

Para comenzar ${ }^{18}$ a responder ${ }^{19}$ esta cuestión, es necesario examinar con más profundidad cuál es la forma en que los seres humanos organizan su conocimiento del mundo.

\section{REPRESENTANDO INFERENCIAS COMPLEJAS «DIFÍCILES»}

\subsection{Patrones de inferencia no-Markov ${ }^{20}$}

Los argumentos hasta ahora expuestos en este trabajo rechazaban en gran parte el argumento de que la existencia de inferencia compleja por sí sola justifique el uso de

${ }^{16}$ Se han hecho serios e impresionantes esfuerzos para remover parte de la confusión de los diagramas de Wigmore y para hacerlos más acertados y eficientes. En especial ANDERSON y TWINING, Anaysis of Evidence: How to do things with facts based on Wigmore's Science of Judicial Proof (Little, Brown \& Co., 1991, republished by Northwestern U. Press, 1998) - N. de T.: hay una segunda edición de este trabajo de 2005, publicada por Cambridge U. Press, en la que también participa David A. SCHUM, reconocido especialista en probabilidad y prueba legal-. Cfr. Schum, 1996: A Probabilistic Analysis of the Sacco and Vanzetti Evidence, Wiley \& Sons. Estos esfuerzos, que continúan, han tenido sin embargo un éxito limitado: el método de grafiar la evidencia Wigmoreano aún no ha sido ampliamente adoptado por los estudiosos del Derecho, los abogados en ejercicio o los jueces. No obstante lo cual, hay signos del creciente interés de los profesionales del Derecho en las estrategias de grafiar Wigmoreanas y neo-Wigmoreanas. Vid. v. gr. PALMER, 2003: Proof and the preparation of Trials (Thomson Lawbook Co.).

${ }^{17}$ Es importante no perder de vista que es difícil construir diagramas, guías, gráficos y símbolos de cualquier clase que sean útiles. Prueba de ello es que el mundo está lleno de señales visuales mal diseñadas. Para más información, ver, TufTE, 1997: Visual Explanations; TuFTE, 1990: Envisioning Information; KAUfMANN, 1999: Visualitation. Using Vision to Think (que incluye una discusión acerca de un «documento lente» que permite a los usuarios ver los documentos «simultáneamente en general y en detalle»).

${ }^{18}$ Este trabajo no intenta discutir todas o incluso muchas de las cosas que son importantes para un diseño acertado de gráficos o guías. El autor no se encuentra cualificado para ello. El trabajo en su lugar examina sólo dos o tres rasgos que parecen ser necesarias para hacer que la técnica de visualización del pensamiento de la prueba de hechos funcione bien. Estos rasgos concretos son también importantes a causa de su implicación en la cuestión general de cómo los seres humanos comprenden y organizan su compresión del mundo en el que viven y actúan.

${ }_{19}$ Aunque no puede haber una respuesta universal a esta pregunta. Los problemas de evidencia e inferencia envuelven una amplia variedad de tareas y problemas y, en correspondencia, una amplia y diversa clase de representaciones visuales pueden intentar ser beneficiosas, al menos lo suficiente para sobrepasar los costes de usarlas.

${ }^{20} \mathrm{~N}$. del T.: Una cadena de Markov, que recibe su nombre del matemático ruso Andrei Andreyevich MARKOV (1856-†1922, Calculo de probabilidad, San Petersburgo: Academia de Ciencias, 1. ${ }^{a}$ ed., 1900, 2. ${ }^{a}$ ed., 1908), es una serie de sucesos, en los cuales la probabilidad de que ocurra un suceso depende del suceso inmediato anterior. En efecto, las cadenas de este tipo tienen memoria, «recuerdan» el último suceso y esto condiciona las posibilidades de los sucesos futuros. Esta dependencia del suceso anterior distingue a las cadenas de Markov de las series de sucesos independientes, como tirar una moneda al aire o un dado. 
apoyo visual en la investigación forense de los hechos y su prueba. El argumento fue rechazado algo presuntuosamente - en gran parte con base en que algunas formas de inferencia compleja son relativamente «simples»- El rechazo fue presuntuoso porque incluso si hay un procedimiento sencillo para abordar largas cadenas de posibles inferencias, es casi seguro que es útil alguna clase de gráfico o lista tabulada para estar al tanto del progreso dirigido a una larga serie de inferencias. Es sin embargo necesario revisar la cuestión de la importancia de visualización de alguna clase en tales contextos. La razón es que en el mundo real las posibles inferencias que han de ser valoradas casi nunca toman la forma de una serie lineal de inferencias. Consideremos el diagrama contenido en la Figura 8.

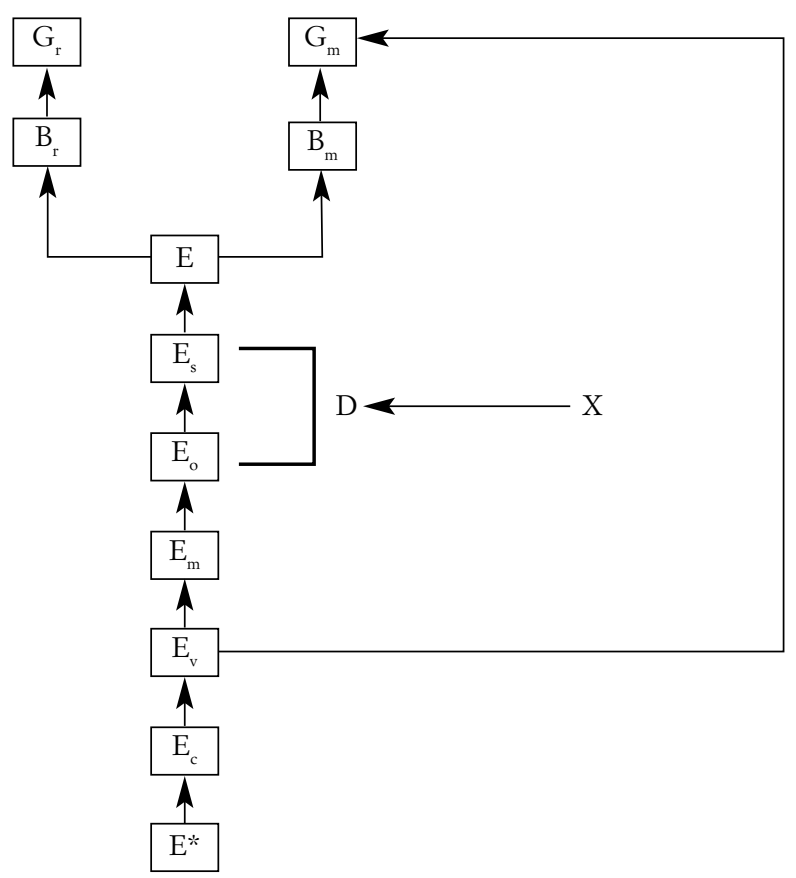

Figura 8

El diagrama de la Figura 8 ilustra el simple hecho de que un enlace en una parte baja de una escala de inferencias puede tener un vástago - es decir, que un escalón, o nodo, en la serie de inferencias enlazadas pueda encontrarse anudado por una flecha que se extienda, no sólo al siguiente escalón de la escala de inferencias, sino a algún escalón superior-. La Figura 8 describe una situación en la que una persona que valora la evidencia cree que la inclinación de un testigo a decir la verdad puede estar influida —o afectada - por alguna proposición ulterior de la cadena de inferencias. Por ejemplo, Walter es interrogado sobre si su hijo Albert escapó o no de prisión. Walter puede encontrarse menos inclinado a declarar la verdad $E^{*}$ sobre la fuga de Albert $E$ que 
de la fuga de otra persona si Walter cree que la información que pueda aportar sobre la fuga de Albert $E$ incrementaría de forma relevante las posibilidades de que su hijo Albert fuese declarado culpable de asesinato. El arco lateral generado saltando a un escalón superior de la cadena expresa la proposición de que la veracidad de la declaración de Walter puede verse afectada por el último hecho en disputa del caso.

En la clase de situación representada en la Figura 8 - una situación en la que hay una posibilidad de que puedan existir enlaces directos entre las partes bajas y altas de la cadena o escala de inferencias-, una persona que valore la evidencia de la fuga $E^{*}$ no debe cortar con la fase anterior de la escala de inferencias antes de haber valorado las posibles conexiones entre la parte baja y la parte alta de la escala de inferencias que está tratando de construir y escalar. En esta situación la clase de estrategia dividir y conquistar que he descrito no es válida. El procedimiento apropiado aquí, por tanto, no puede consistir en abordar cada inferencia de la serie de inferencias en el orden en que las mismas aparecen en la cadena o escala. La existencia de enlaces laterales que salten los nodos equivale a una confirmación de que algunos de los escalones de la escala de inferencias deben ser considerados «en forma independiente a su orden».

Situaciones de la clase representada por la Figura 8 son la norma más que la excepción. Por ejemplo, un conjunto de atributos testimoniales - la memoria, la veracidad, la capacidad sensorial, etc. de los testigos- puede verse afectada por la clase de suceso o situación cuya existencia o no se declara; la gente es más capaz de percibir, recordar, etc., ciertos tipos de sucesos que otros.

La teoría de los gráficos enseña que la complejidad de una red y la dificultad de desarrollar las tareas en una red de posibles inferencias se encuentran no solo en función del número de nodos de la red ${ }^{21}$. La complejidad de una red de inferencias y la dificultad de la tarea que describe se encuentra igualmente en función del patrón de enlaces entre los nodos en la red. La existencia de enlaces «laterales» de la clase de los que encontramos en la Figura 8 incrementa en gran medida la complejidad de la red de inferencias ${ }^{22}$.

Los gráficos del tipo de la Figura 8 son redes no-Markov. Las redes Markov limitan los tipos de dependencias que pueden ocurrir entre probabilidades condicionales en las redes de inferencia, y así limitan las demandas de cálculo que la red de inferencia probabilística puede generar. A este trabajo sin embargo no le concierne la cuestión de las demandas de cálculo generadas por la utilización de redes de inferencias con patrones no-Markov; pues lo que a este trabajo concierne ahora no es intentar desarrollar procedimientos que minimicen la dificultad de cálculo dependiente de

${ }^{21}$ La complejidad de una red de inferencias se encuentra igualmente en función del número de enlaces, o flechas, de la red. Una red es un tipo de gráfico. El volumen del problema de cálculo descrito por un gráfico es $g(n)=2^{n}$ donde $n$ es el número de ingredientes (nodos y flechas) de tal gráfico. Vid. SCHum, D., 1994: Evidential Foundations of Probabilistic Reasoning, $\$ 4.5$, at, 181-182.

${ }_{22}$ El número de enlaces puede incrementarse exponencialmente si se permiten los enlaces laterales. Por ejemplo, consideremos un «gráfico completo» $-K_{n}-$, un gráfico en el que cada nodo se encuentra conectado con cada uno de los otros nodos. Si $n$ representa el «número de nodos», el número de flechas —y, por tanto, el número de dependencias entre las probabilidades condicionales en una red de Bayes (un tipo especial de gráfico- es igual a $n(n-1) / 2$. vid. Eric Weisstein's World of Mathematics, http://mathworld.wolfram.com/CompleteGraph.html. 
probabilidades condicionales. Pero el hecho de que las redes no-Markov incrementen en gran medida la dificultad de cálculo de las probabilidades condicionadas en las redes de inferencias es sugestivo: induce a sospechar que la clase de patrón de posibles inferencias analizado en la Figura 8 incrementa en gran medida tanto la complejidad cuanto la magnitud de la tarea de valorar las posibles inferencias y que, con base en ello, la visualización de al menos algunas clases de problemas de evidencia e inferencia pueden ayudar sustancialmente a la gente que debe ordenar tan complejo y difícil trabajo.

No obstante, mientras que la complejidad y dificultad de los patrones de inferencia tales como los descritos en la Figura 8 pueden por sí solos justificar la sospecha de que algunos métodos de visualización de problemas de evidencia e inferencia en asuntos legales pueden ser útiles, prefiero no utilizar el argumento de que el beneficio de la visualización depende completamente de la indubitada existencia de la clase de «compleja inferencia» que encontramos en la Figura 8, pues hay argumentos incluso mejores para sostener la afirmación de que la representación visual de problemas de evidencia e inferencia puede ser beneficiosa. Además, dichas consideraciones adicionales sugieren igualmente cómo pueden ser visualizados los problemas del tipo de la Figura 8 de modo que sea útil ${ }^{23}$.

\section{REPRESENTANDO ACTIVIDAD INFERENCIAL DIVERSA, DINÁMICA Y CÍCLICA}

\subsection{Principios generales}

Para los actuales propósitos tres características del proceso de valoración que utilizan las personas son particularmente importantes:

i) La actividad inferencial de las personas es dinámica; ocurre dentro del tiempo y también al margen del mismo.

ii) La actividad inferencial de las personas es cíclica; los engaños del tiempo y la imaginación humana requieren con frecuencia que el terreno inferencial anteriormente atravesado sea revisado.

iii) La inferencia que hacen las personas implica diversas estrategias para organizar la evidencia, y ningún algoritmo o regla conocidos especifica cómo interactúan recíprocamente las referidas estrategias.

Estas características de la inferencia que efectúan las personas sugieren que las ventajas de representaciones visuales son sustanciales y, quizás más importante, sugiere que ciertos tipos específicos de visualización es probable que sean particularmente beneficiosos.

${ }^{23}$ Los argumentos empleados en este trabajo sugieren que el método de representación que encontramos en la Figura 8 es normalmente insuficiente para los complejos problemas del mundo real, cuya solución no puede ser completamente automatizada. De hecho, la teoría de los gráficos muestra que la estructura de gráficos como los que se recogen en la Figura 8 hace imposible, en muchas instancias, calcular la solución incluso si las proposiciones de los gráficos y los enlaces entre ellos pueden ser expresadas matemáticamente (como las probabilidades condicionales y los ratios de probabilidad). 


\subsection{Multiplicidad de métodos de organizar la evidencia: «Plan de Organización» ${ }^{24}$}

La investigación para ser eficaz —y, también, yo creo, la valoración eficaz de hipótesis sobre hechos en general- implica un conjunto de métodos de organizar o de ordenar la evidencia ${ }^{25}$. El cuadro 9 es una representación de algunos importantes métodos de organización de la prueba (a este conjunto de estrategias de organización de la evidencia le he otorgado el mote de Plan Marshal).

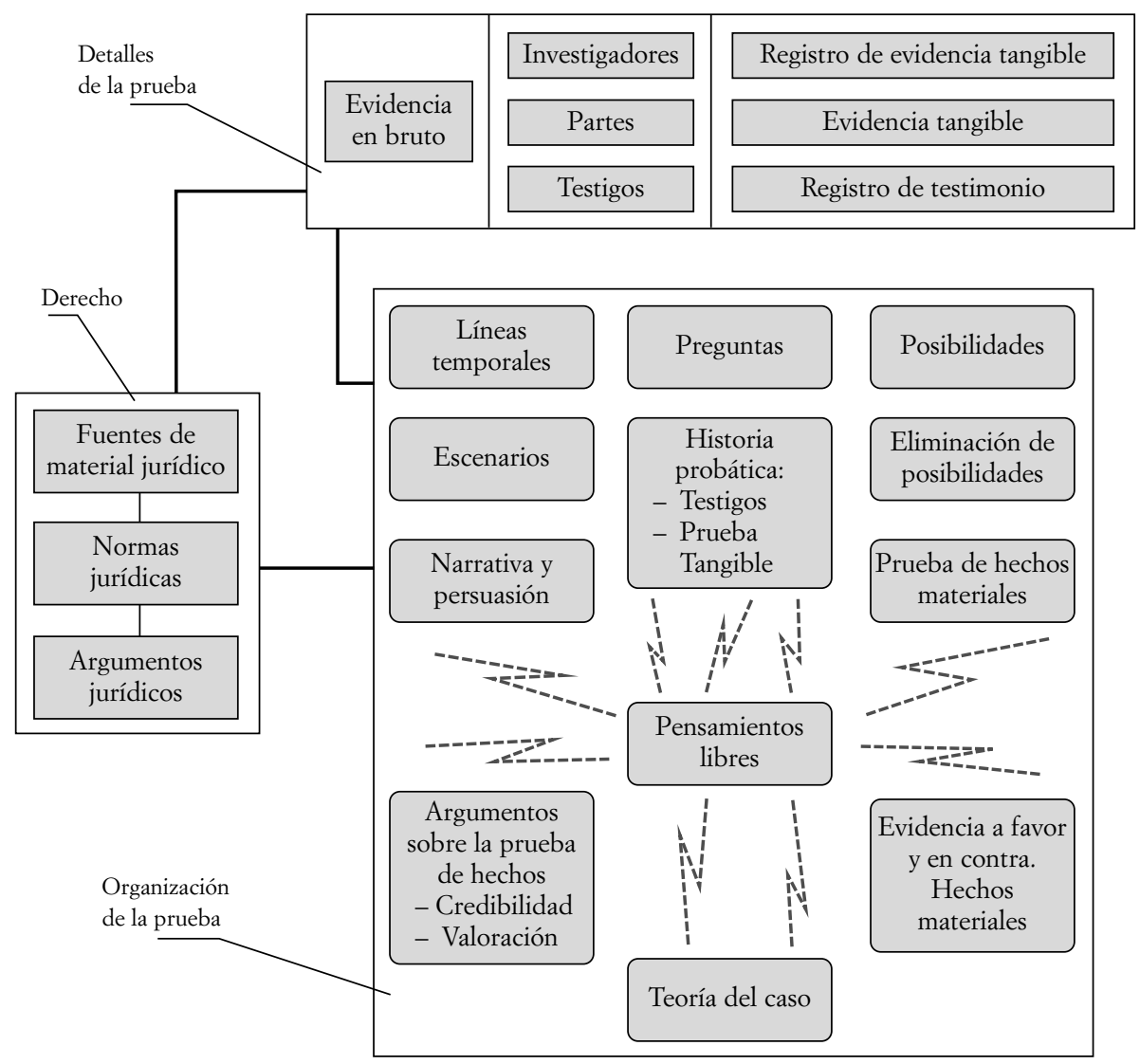

Figura 9

${ }^{24} N$. de T.: Se trata de un juego de palabras que se pierde en español «Marshaling Evidence» (organizar la evidencia) y «Marshal Plan» (Plan de Organización y también el conocido «Plan Marshal»).

${ }_{25}$ TILleRS y SCHUM, 1991: A theory of Preliminary Fact Investigation, 24 U.C. Davis L. Rev. 931. See «preprint» en http://tillers.net/fpaper.html. Véase también SCHUM, The Evidential Foundations of Probabilistic Reasoning, $\mathbb{S}$ 9.4-9.4.2 (Wiley \& Sons, 1994, republished by Northwestern U. Press, 2001); SchUM, 1999: Marshaling Thoughts and Evidence During Fact Investigation, 40 S. Tex. L. Rev. 401. 


\subsection{Ilustración de las interacciones entre las distintas estrategias de organización de la evidencia: líneas temporales y escenarios}

El espacio no nos permite aquí la discusión de los detalles de todos los variados métodos de organizar y de recopilar la evidencia representada por los iconos de la Figura 9. Analizaré sólo algunos de esos métodos de organizar la evidencia y comenzaré con una breve discusión acerca de las líneas temporales y los escenarios, así como las relaciones entre ellas. Hablaré más adelante del método de organización que yo denomino «teoría del caso».

\subsection{Definición de las líneas temporales y de los escenarios}

Una línea temporal es un orden cronológico posible de una serie de acontecimientos posibles. Los acontecimientos posibles son aquéllos sugeridos por la evidencia. Un escenario, por el contrario, es una hipótesis sobre las conexiones o las influencias posibles entre los acontecimientos posibles en un cierto lapso temporal; un escenario, por tanto, es una hipótesis sobre la influencia de acontecimientos anteriores en acontecimientos subsiguientes. Además, aunque que un escenario puede incluir los acontecimientos que tienen cierto soporte fáctico, puede también contener acontecimientos posibles para los cuales no hay otro soporte que la imaginación de las personas y los otros acontecimientos del escenario: en otras palabras, en los escenarios se permiten los acontecimientos puramente conjeturales.

\subsection{Relación entre el número de detalles probatorios y el número de las líneas temporales}

Cantidades pequeñas de evidencia pueden generar una cantidad grande de secuencias cronológicas distintas de sucesos posibles. Escojamos un ejemplo sencillo. Supongamos que tenemos únicamente los informes de los cuatro hechos siguientes:

$\mathrm{XX}$ afirmó: «Nunca ha existido un hombre tan detestable como YY».

XX golpeó la cabeza de YY.

YY golpeó la cabeza de XX.

El cráneo de YY se rompe. chos?

¿Cuántas hipótesis o posibilidades reales pueden sugerir o apoyar estos cuatro he-

Asumamos que los informes de estos cuatro hechos son perfectamente creíbles y dignos de crédito. Así, nuestras reflexiones sobre estos cuatro hechos, se refieren solamente a su orden cronológico.

Incluso si asumimos esta premisa para simplificar, es bastante obvio que los informes de los cuatro acontecimientos pueden apoyar o sugerir una variedad de hipótesis o posibilidades fácticas.

Por ejemplo, los informes de los cuatro acontecimientos sugieren la siguiente secuencia posible de los posibles acontecimientos (Secuencia n. ${ }^{\circ}$ ): 
YY golpea a XX en la cabeza.

XX golpea la cabeza de YY.

La cabeza de YY se rompe.

XX afirmó: «Nunca ha existido un hombre tan detestable como YY».

La siguiente secuencia posible de acontecimientos posibles (Secuencia n. ${ }^{\circ}$ 2) también es apoyada por los informes de los cuatro acontecimientos descritos arriba:

XX afirmó: «Nunca ha existido un hombre tan detestable como YY».

XX golpeó la cabeza de YY.

YY golpeó la cabeza de XX.

El cráneo de YY se rompe.

La secuencia n. ${ }^{\circ} 3$ también es apoyada o sugerida por los informes anteriormente descritos de los cuatro acontecimientos:

YY golpeó la cabeza de XX.

El cráneo de YY se rompe.

XX golpeó la cabeza de YY.

XX afirmó: «Nunca ha existido un hombre tan detestable como YY».

Resulta innecesario catalogar cada secuencia posible de los cuatro acontecimientos. Es suficiente observar que la Secuencia n. ${ }^{\circ} 1$, la Secuencia n. ${ }^{\circ} 2$, y la Secuencia n. ${ }^{\circ} 3$ no son hipótesis sobre hechos idénticos; son diferentes.

Este punto puede ser generalizado: si $n=$ el número de acontecimientos, el número de secuencias temporales posibles de esos acontecimientos es $n !{ }^{26}$. Esto significa que con apenas cinco (5) acontecimientos sobre los que se informe, el número de las secuencias posibles del acontecimiento es 120 . Si hay apenas diez (10) acontecimientos sobre los que se informe, el número de las secuencias cronológicas posibles del acontecimiento se eleva a 3.628.800.

El número de posibles líneas temporales aumenta dramáticamente si los acontecimientos tienen una duración en el tiempo y pueden solaparse. El número de posibles líneas temporales otra vez aumenta dramáticamente si se piensa que las diferencias en que la cantidad de tiempo entre los acontecimientos produce distintas líneas temporales ${ }^{27}$.

\subsection{Interacciones entre escenarios y líneas temporales}

Aunque los escenarios y las líneas temporales difieran (en la forma mencionada), las líneas temporales en cualquier caso están en relación con escenarios. Por ejemplo, aunque las líneas temporales no son ellas mismas escenarios, sí tienen la capacidad de sugerir escenarios: los sucesos colocados en la línea temporal son escalones sobre los

${ }^{26} N$. de T.: Para los juristas: $n$ ! no es un error tipográfico, significa «ene factorial», y, en el lenguaje de la rama matemática denominada «combinatoria», es el número de ordenaciones diferentes de «n» elementos. Esto es, responde a preguntas como ¿Cuántas ordenaciones pueden hacerse de un mazo de 52 cartas? Así, el número de combinaciones de cinco elementos (5!) es de $5 \times 4 \times 3 \times 2=120$, etc.

${ }^{27} \mathrm{La}$ cantidad de tiempo entre sucesos puede ser muy significativa. Por ejemplo, si hay informes sobre dos sucesos «XX grita: "Odio a YY" y "XX disparó a YY”». Una cosa es la hipótesis de que el suceso «XX gritó: "Odio a YY" » ocurrió 60 segundos antes de que «XX disparó a YY», y otra muy distinta es la hipótesis de que el suceso «XX gritó "Odio a YY”» tuviera lugar 60 años antes de que «XX disparó a YY». 
que los escenarios —hipótesis causales que incluyen sucesos puramente conjeturalesa menudo se sostienen.

Los siguientes símbolos pueden ser usados para construir eventos cronológicos, o líneas temporales:

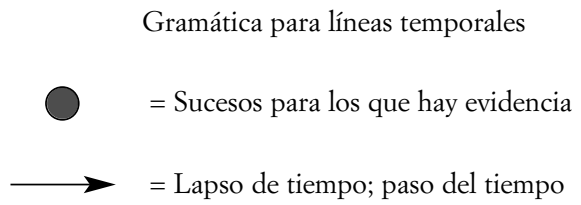

Esta notación se puede utilizar para construir líneas temporales tales como la que se muestra en la Figura 10.

Andamiaje del escenario

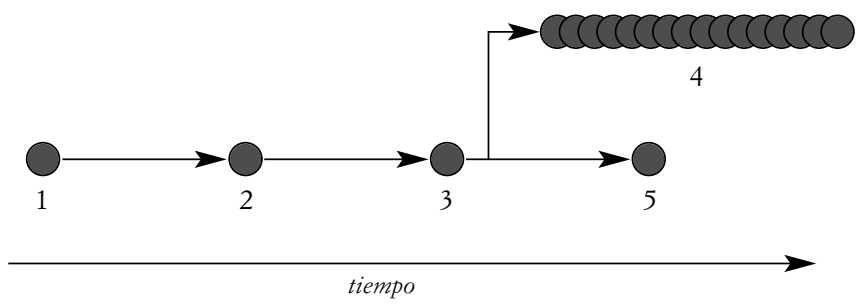

$1=$ Pedro Demandante (PD) entra en la tienda

2 = Alguien dispara a Pedro Demandante

$3=\mathrm{PD}$ recobra la consciencia y es llevado al hospital

4 = Quique El Sucio (QS) desaparece y no reaparece

$5=\mathrm{PD}$ se somete a tratamiento médico y cirugía

Figura 10

La notación mostrada arriba puede ser utilizada también para construir escenarios:

Gramática para escenarios

= Sucesos para los que hay evidencia

$\bigcirc \quad=$ Relleno de huecos; sucesos hipotéticos; sucesos para los que carecemos de otra evidencia distinta que el escenario

$\longrightarrow \quad=$ Lapso de tiempo; paso del tiempo 
La línea temporal en la Figura 10 puede provocar o sugerir la formación del escenario de la Figura 11.

Escenario 1

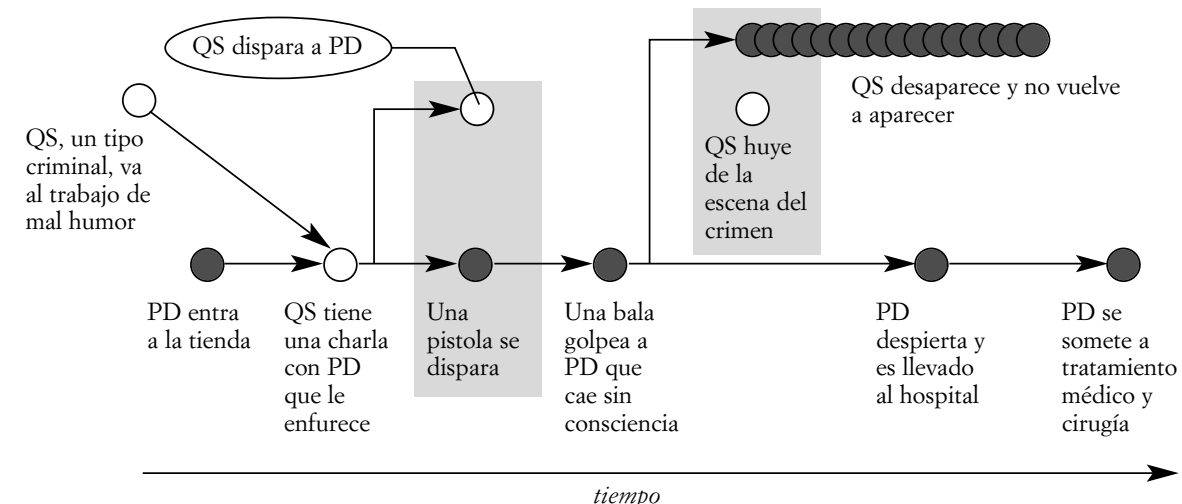

tiempo

\begin{aligned} \hline & $=$ Suceso sobrante en Autos \\ $\mathrm{PD} & =$ Suceso hipotético \\ $\mathrm{QS} & =$ Quique el Sucio \end{aligned}

Figura 11

Las hipótesis causales pueden cubrir los huecos de sucesos en las líneas temporales porque aunque los sucesos en las líneas temporales sean solamente sucesos «posibles», en las líneas temporales los sucesos posibles siempre tienen algún soporte fáctico. Esto es importante para el análisis de escenarios en procesos judiciales porque cuando las partes tienen en mente la posibilidad de un proceso judicial, intentan reconstruir escenarios que tengan posibilidades plausibles de ser considerados ciertos. En estos supuestos, el soporte evidencial proporciona razones para pensar que un concreto escenario puede ser verdad, más allá de lo que la imaginación desbordada pueda sugerir.

\subsection{Contracción y expansión de las posibilidades fácticas por medio de escenarios}

Los escenarios pueden reducir el número de posibles secuencias de sucesos en juego. Hay al menos dos formas en que esto puede ocurrir: La primera, porque algunas secuencias de sucesos posibles no ocurren en los escenarios porque puede entenderse razonablemente que el suceso anterior de una secuencia temporal tendrá influencia sobre el suceso siguiente, aunque el nexo causal entre los dos sucesos no necesariamente existe si el orden es invertido. Por ejemplo, es razonable pensar que la caída de una roca 
del cielo puede causar un agujero en el suelo, pero no es admisible pensar que la aparición de un agujero en el suelo pueda causar la caída de una roca del cielo. La segun$\mathrm{da}$, porque algunos sucesos posibles de las líneas temporales se convierten en posibilidades carentes de interés en los escenarios, ya sea porque ciertos sucesos de las líneas temporales carecen de soporte probatorio suficiente, ya sea porque dichos sucesos no son sugeridos suficientemente por los sucesos ya admitidos del referido escenario.

Pero los escenarios también tienen una característica que les permite la expansión de las posibilidades fácticas, y además es un tipo de expansión que no puede ocurrir en las líneas temporales. En los escenarios, son admisibles los sucesos puramente hipotéticos — esto es, sucesos sin soporte evidencial directo- - Si se permite a la imaginación vagar libremente, un gran número de escenarios y sucesos hipotéticos pueden ser construidos alrededor de los hechos a disposición del tribunal, los sucesos que tienen círculos negros denotan sucesos que tienen soporte evidencial. Por ejemplo, la Figura 12 muestra un segundo escenario colgado sobre el andamiaje de la línea temporal de la Figura 10.

Escenario 2

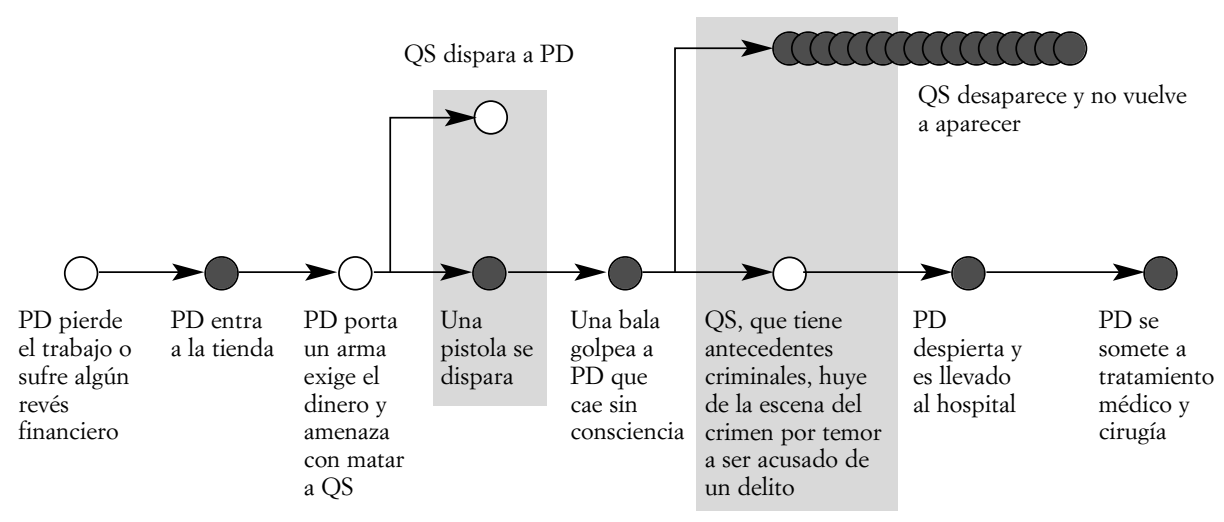

Figura 12

Muchos otros escenarios son posibles.

\subsection{Lecciones generales de los ejemplos de interacción entre líneas temporales y escenarios}

La clase de interacción que he expuesto entre escenarios y líneas temporales ocurre, con carácter general, entre otras formas de organización de la evidencia. Estas interacciones tienen tres importantes características:

1. ${ }^{\mathrm{a}} \quad$ Cada uno de los métodos de organización de la prueba implicados en tales interacciones tienen capacidad de generar - y con solo un poco de esfuerzo y detenimiento, cada estrategia puede normalmente generarlas- estructuras de gran densidad e intrincación. 
2. $\quad$ Las interacciones entre las estructuras generadas por las variadas estrategias de organización de la evidencia no se encuentran reguladas por ninguna regla o algoritmo discernible.

3. ${ }^{2} \quad$ Las interacciones entre las variadas formas de organizar la evidencia son cíclicas más que acíclicas:

Por ejemplo, una línea temporal puede sugerir un escenario, que a su vez puede sugerir la posibilidad de alguna nueva evidencia, que una vez disponible, puede traer como resultado un conjunto de líneas temporales, que pueden nuevamente sugerir otros escenarios, y así sucesivamente.

\subsection{Obstáculos a la visualización explícita de problemas de evidencia e inferencia}

La complejidad de los caracteres enunciados en el apartado precedente genera una variedad de obstáculos ante cualquier intento de hacer explícito el proceso de interacción y valoración de los hechos, o de hacer que el proceso de inferencia de los hechos sea inteligible para el pensamiento consciente. Un obstáculo es el problema de la coordinación o armonización de las múltiples estrategias de organización de la evidencia que los seres humanos usan o deberían usar para hacer conjeturas sobre cuestiones de hecho bien fundamentadas en los procedimientos judiciales. Aunque no existe ninguna regla que me haya sido posible encontrar para describir la manera en la que las variadas estrategias de organización se relacionan, estas estrategias de organización sin duda se influyen mutuamente. Por ejemplo, si encontramos inconsistencias entre las variadas estructuras y complejos generados por los múltiples métodos de organización de la evidencia mostrados en la Figura 9, ello puede llevar a que todo el conjunto se derrumbe. Puede llevarnos a la conclusión de que, o bien la evidencia e información disponibles no ofrecen soporte suficiente para algunas hipótesis de hecho, o bien que una persona pertrechada sólo con las conclusiones y juicios extraídos por medio de varias estrategias de organización aún no está en disposición de tener suficiente base para hacer un juicio correcto acerca de algún problema de evidencia e inferencia.

\subsection{Una representación general de armonización de los resultados de las diversas estrategias de organización de la evidencia}

El diagrama que contiene la Figura 13 ilustra la clase de coordinación o armonización que el investigador, el abogado en juicio o el juzgador de los hechos debería intentar conseguir - ¿Y quizá debe conseguir? - para resolver satisfactoriamente el problema de la evidencia y la inferencia en procedimientos legales.

La Figura 13 representa la clase de posición que las partes, $v$. $g r$ los abogados, pueden aspirar a alcanzar cuando participan en el proceso probatorio de hechos en cuestiones legales.

Adviértase que la Figura 13 es una representación ${ }^{28}$.

${ }^{28}$ Aunque, dada mi exposición de las relaciones entre distintas estrategias de organización de la evidencia —relaciones que pueden ser justamente caracterizadas como «evocativas»— el diagrama de la Figura 13 no es, 


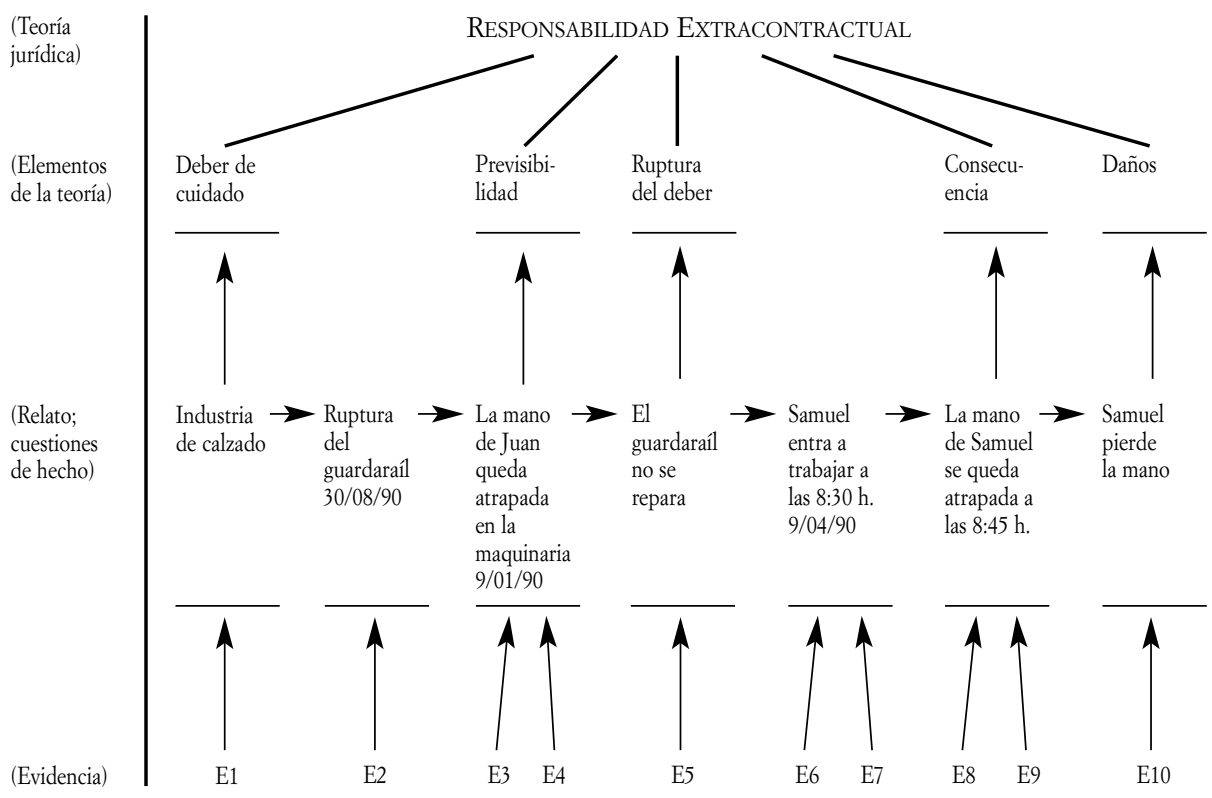

Figura 13

La pregunta es si tal representación —o cualquier representación o diagrama similar- es de alguna utilidad a las partes, como los abogados en juicio, para conseguir sus objetivos. Esta es la cuestión fundamental que intenta responder este trabajo.

\subsection{Los potenciales beneficios de representaciones generales de los problemas de evidencia e inferencia}

Hay razones para pensar que esta clase de representaciones generales puede ser útil a aquéllos que toman parte de una investigación forense y que pretenden probar algo.

En primer lugar, es útil tener una guía que dé cuenta de una conjetura razonable acerca del camino que uno debería o podría tomar en el intento de investigar o probar un caso en algún foro jurídico. Se necesita algún plan de ataque - si uno no está ya ocupado en una actividad relacionada con una prueba sin fin-. El mero hecho de que uno pueda tener que modificar o incluso abandonar un plan de ataque tentador no demuestra que no se necesite uno. Es necesario hacer algunas apuestas relacionadas con la actividad probatoria si queremos tener éxito.

En segundo lugar, la clase de representación que hay en la Figura 13 es útil porque proporciona un modo coherente y significativo de poner las partes o problemas de un

estrictamente hablando, una red. En términos de teoría de los gráficos, la Figura 13 no es una red auténtica, pues las flechas entre los nodos de la Figura 13 no representan relaciones lógicas, sino que representan, hablando en términos generales, relaciones psicológicas posibles. 
caso juntos. Los estudios efectuados por psicólogos y otros muestran o sugieren de forma insistente que la capacidad de la gente para recordar y retener información, generalmente y, de forma muy perceptible, aumenta si se organiza la información de modo que sea significativa para ellos de acuerdo con algún patrón que puedan discernir y mantener en su mente ${ }^{29}$.

En tercer lugar, el diagrama de la Figura 13 es útil incluso si deja fuera una gran cantidad de detalles. De hecho el diagrama es útil precisamente porque deja fuera del mismo una gran cantidad de detalles.

La capacidad de las personas para dotar de sentido las cosas depende de la simplificación. Los detalles, cuando son excesivos, confunden. La confusión impide el pensamiento. La exclusión de detalles innecesarios facilita una perspectiva global, una perspectiva sintética, la capacidad de ver las relaciones entre las partes principales de un problema complejo. Esta clase de perspectiva sintética o global es esencial para el funcionamiento efectivo de cualquier actividad compleja que implique la utilización simultánea de varios procesos. Intentar resolver un problema de evidencia e inferencia complejo es un poco como intentar tirar de un carro con un burro y un caballo; has de saber cómo trabaja el burro y como trabaja el caballo, pero también has de saber cómo trabajan ambos juntos. ¡Y pobre de ti como tengas que usar una hiena y un leopardo juntos!

\subsection{Un requisito básico para el uso de guías y representaciones generales en la inferencia: las representaciones deben permitir al usuario ver la representación general mientras se conservan importantes detalles en mente}

El pensamiento sintético es esencial, pero no es la única forma importante de pensamiento para la valoración de la evidencia. La comprobación de los aspectos de detalle de la evidencia, los problemas de la evidencia y los argumentos acerca de la evidencia son igualmente importantes; son esenciales. La importancia incuestionable de los detalles presenta dos enigmas: El primero, las personas son incapaces de mantener todo lo que saben o creen en la cabeza al mismo tiempo. ¿Cómo se las arreglan para organizar la inferencia entonces? El segundo, si ambas perspectivas, la granular y la global son importantes, pero las personas carecen de la capacidad de mantener todo en la cabeza al mismo tiempo. ¿Es posible hacer representaciones que permitan a las personas ver la representación general y las partes menores simultáneamente?

Este trabajo no se dirige a resolver el primer enigma. En su lugar, este trabajo parte de la base de que las personas de alguna manera se las arreglan para hacer uso de grandes cantidades de detalles que con toda probabilidad no pueden mantener en la mente en su integridad durante todo el tiempo. La intuición de la que las personas ha-

${ }_{29}$ Vid. v. gr. DAVIS y FOLLETE, 2001: Foibles of Witness Memory for Traumatic/High profile Events, 66, J. Air \& Com., 141-1443 («se ha demostrado de forma consistente que un procesamiento más profundo que produce una mejor memoria»). Cfr. CADWELL, y PERRIN, 2001: Richard Gabriel \& Sharon R. Gross, 76 Notre Dame L. Rev., 423-493 («la información proporcionada por estudios empíricos muestra la «pasmosa» capacidad de las personas para recordar imágenes»). 
cen gala para conseguir este resultado es fundamental — porque esta intuición cuenta con la importante y plausible hipótesis de que el cerebro de los seres humanos es capaz de actualizar pensamientos y creencias que no se encuentran en su integridad en la mente-. Así, por ejemplo, quizá las personas puedan tener un sensación o sentimiento para las relaciones entre conjuntos y partes, en parte porque los cerebros humanos tienen la capacidad de actualizar pensamientos que una vez fueron explícitos - que una vez fueron el foco de nuestros pensamientos- pero que ahora son tácitos, y descansan en la periferia de la mente y del pensamiento explícito.

La tesis de este trabajo parte de la premisa (iJustificada!) de que el cerebro o nuestras cabezas hacen uso de los pensamientos, juicios, creencias, recuerdos, inferencias, suposiciones, etc., sin tener toda la materia en su totalidad en mente. A pesar de la dificultad de hacerlo, las personas de alguna manera se las arreglan para organizar partes grandes y pequeñas de problemas simultáneamente. Es, por tanto, justo conjeturar que la habilidad de las personas para desarrollar esta difícil tarea es en parte atribuible a su capacidad de pensar acerca de cosas incluso cuando no se encuentran de forma explícita o directa atendidas por alguno de los pensamientos que ellos tienen acerca de tales cosas.

Esta premisa (la hipótesis en cursiva) es el fundamento básico para mi tesis acerca de los beneficios de ciertas clases de representaciones visuales de problemas de evidencia e inferencia. Mi principal argumento es que hay necesidad de apoyos visuales que mejoren la capacidad de las personas para hacer uso de los pensamientos pertinentes que tienen en la trastienda de sus cerebros.

\subsection{Dos clases diferentes de proceso cognitivo «tácito»}

Hay algunos procesos mentales que (en la actualidad) no pueden ser controlados (excepto en su periferia) por la atención consciente. La percepción visual es un ejemplo. Aunque generalmente controlamos donde movemos nuestros ojos, no podemos imponer al cerebro un cambio en el modo en que procesa los estímulos visuales que le envía el sentido de la vista. Pero no todos los procesos mentales tácitos se encuentran tan profundamente guardados.

Algunos procesos mentales sólo son «tácitos» en el sentido de que las personas no están atendiéndolos, esto es, no son objeto de su atención primordial. Algunos de los ejemplos de las operaciones de organización que hemos analizado en este trabajo son ejemplos de pensar que es sólo comparativamente tácito, pensar y pensamiento que no se encuentran completamente bajo el, o inaccesibles al, pensamiento explícito. Por ejemplo, algunas de las cosas que las personas mantienen en la recámara de sus cabezas son pensamientos que una vez fueron explícitos, que una vez centraron comparativamente la atención directa y que llegaron a ser relativamente tácitos sólo porque la atención primordial del actor se desplazó a otros asuntos.

Las personas no pueden prestar atención directa o intensa a todo al mismo tiempo, cuando una persona dirige su atención a cierta cuestión, la consecuencia es que reduce la atención que presta a otras. Pero cuando la atención se encuentra enfocada en alguna materia, muchos pensamientos sobre otras materias respecto de los que la mente se encuentra relativamente distraída continúan siendo importantes y muchos de ta- 
les pensamientos continúan trabajando y agitándose en la trastienda de la mente. La tesis central de este trabajo es que la gente tiene pensamientos medio-en-mente, y que tales pensamientos medio-en-mente, los pensamientos que se encuentran en la trastienda del cerebro, son importantes para el razonamiento bumano sobre hipótesis de hecho.

\subsection{Aplicando y comprobando la hipótesis de la importancia de los pensamientos situados en la periferia de la atención de las personas}

Espero poder comprobar la hipótesis de la importancia de los pensamientos medio-sumergidos a través del desarrollo de algún programa que ayude a la gente a hacer uso de los pensamientos medio-en-mente, y sus pensamientos semi-tácitos y semi-explícitos. Espero crear un programa que ayude a la gente a mantener en mente y llamar y hacer un mejor uso de o mejorar el funcionamiento o trabajo de los pensamientos que tienen medio-en-mente. Específicamente, espero desarrollar un programa que haga cosas tales como las siguientes: i) representar con claridad las líneas generales de un problema de evidencia e inferencia mientras representa más débilmente y menos evidentemente pero todavía visibles los detalles de la estructura general; ii) permitir a los usuarios del programa cambiar rápidamente de una forma de organizar la evidencia mientras se describe más débilmente (en el monitor) el método que inmediatamente antes captaba la atención del usuario; iii) permitir al usuario del programa cambiar a alguna parte de alguna parte de una estructura de la organización de la evidencia mientras la estructura circundante permanece menos evidente pero todavía visible y, quizá, también las líneas principales de otras estructuras de organización de la evidencia (colaboraré con un programador y espero que hagamos uso de herramientas tales como contraste y color y representación en múltiples dimensiones).

\subsection{La importancia del juicio subjetivo en el desarrollo de representaciones detalladas}

$\mathrm{El}$ argumento que se presenta en este trabajo sugiere que en algunos o muchos episodios del razonamiento humano la estrategia de dividir y conquistar problemas de evidencia e inferencia - esto es, la táctica de trabajar sobre una escala de inferencias un escalón cada vez, por ejemplo- es, por varias razones, difícil de practicar; y lo es porque, $v$. gr. el pensamiento humano cuando funciona adecuadamente utiliza múltiples métodos de organización de la evidencia cuyas interacciones no son gobernadas por ninguna regla o algoritmo discernible, lo que es tanto como decir que si la exposición general aquí efectuada, en relación con la forma en que las personas usan las variadas estrategias de organización y análisis, es correcta, es francamente difícil partir un gran problema en piezas más pequeñas, valorar una de estas piezas, dejar el problema o cuestión analizada atrás, avanzar hasta la siguiente pieza del rompecabezas, y repetir este proceder hasta que el trabajo de valoración se encuentre completamente terminado (una dificultad que presenta esta estrategia aparentemente sensata es que a menudo es necesario volver atrás y revisar las piezas previamente analizadas del gran rompecabezas inferencial y los complejos cuyas interacciones deben ser revisados pueden interac- 
tuar entre sí en una gran variedad de formas. Otra dificultad es la existencia de enlaces generados por saltos en las redes de inferencias).

Todo el debate sobre el carácter intrincado de los problemas de evidencia y el carácter intrincado del razonamiento y pensamiento acerca de problemas de evidencia no demuestra - y no está diseñado para hacerlo- que las personas son generalmente incapaces de razonar sobre cuestiones fácticas en asuntos legales. Pero lo que aquí se ha expuesto sobre la complejidad y espontaneidad de las operaciones mentales sugiere que la gente que se encuentra ocupada en la actividad inferencial puede perder la pista de sus propios pensamientos.

Desgraciadamente, las mismas consideraciones sugieren que es extraordinariamente difícil y consumiría una gran cantidad de tiempo desarrollar representaciones que capten todas las dimensiones y todos los aspectos de la tarea que la mente debe asumir cuando se ocupa de la actividad inferencial. Esta obvia conclusión sugiere otra igualmente obvia — pero también importante- conclusión: los diagramas que representan el pensamiento humano sobre la evidencia pueden ser valiosos, pero no se debe olvidar que esos diagramas son normalmente apoyos y que si tales apoyos son usados y la manera en que son usados depende de su utilidad en y por el cerebro del usuario de tales representaciones o imágenes visuales. Luego, cualquier sistema que pretenda sostener la actividad y proceso inferencial de las personas debe tener en cuenta que representaciones detalladas de la evidencia y el razonamiento acerca de la evidencia debería construirse sólo en la consideración de que el desarrollo de representaciones detalladas es útil en y para el cerebro del observador de un problema de evidencia e inferencia complejo y difícil.

\subsection{Relaciones entre juicio subjetivo y rigor científico}

El programa que tengo en mente debería tener propiedades y tendencias de tipo Gestalt $^{30}$. Pero no hay nada anticientífico acerca de la clase de programa que desearía desarrollar. Es completamente posible y probable que el análisis de algunos sectores de un problema de prueba de hechos pueda ser automatizado. Además, por ejemplo, existen todas las razones del mundo para creer que partes de algunos problemas hacen surgir cuestiones que pueden ser abordadas con los métodos de la ciencia dura, tales como genética, física y demás (Mi futuro colaborador se encuentra desarrollando métodos de extracción de datos que quizá puedan detectar en algunas instancias fraudes financieros).

${ }^{30} \mathrm{~N}$. de T.: La Psicología de la gestalt es una corriente de pensamiento dentro de la psicología moderna, surgida en Alemania a principios del siglo xx. El término Gestalt proviene del alemán y no tiene una traducción única, aunque se lo entiende generalmente como forma. Sin embargo, también podría traducirse como figura, configuración e, incluso, estructura o creación. La escuela de la Gestalt parte de que la mente configura, a través de ciertas leyes, los elementos que llegan a ella a través de los canales sensoriales (percepción) o de la memoria (pensamiento, inteligencia y resolución de problemas). En nuestra experiencia del medio ambiente, esta configuración tiene un carácter primario sobre los elementos que la conforman, y la suma de estos últimos por sí solos no podría llevarnos, por tanto, a la comprensión del funcionamiento mental. Este planteamiento se ilustra con el axioma el todo es más que la suma de las partes, con el cual se ha identificado con mayor frecuencia a esta escuela psicológica (Wikipedia). 


\section{CONCLUSIONES}

Hace ya tiempo que este trabajo brillaba bajo el foco de mi mente, había una amplia base para creer que algunas clases de imágenes y representaciones visuales podían mejorar la calidad de la inferencia fáctica en asuntos legales. En sus vidas normales, las personas en ocasiones recurren a gráficos, diagramas, cuadros, ideográmas y otras representaciones visuales cuando intentan resolver las cuestiones a varias clases de problemas — por ejemplo, cuando consideran cuestiones tales como «¿cuál es la forma más rápida de ir a East Harlem?» o un complejo de cuestiones relacionadas tales como «¿debería abandonar la enseñanza y desarrollar programas?», «¿soy demasiado viejo para eso?», «¿qué diría mi esposa?» «¿Cómo pagaré mis facturas?», «¿qué pasa si enfermo?». No hay una buena razón para pensar que la utilidad de todas las representaciones visuales se desvanezca cuando la posibilidad o realidad de un proceso judicial proyecte su sombra sobre el juicio y acción humanas.

La pregunta más interesante e importante es qué clase de guías, gráficos, representaciones y cuadros pueden conseguir mejorar la calidad de la inferencia humana.

Esta interesante e importante cuestión no admite una respuesta universal. La inferencia humana - sea en asuntos jurídicos o no-implica una enorme variedad de operaciones cognitivas - tales como los métodos de pensamiento que encontramos, por ejemplo, en astrofísica, previsión meteorológica, psiquiatría y deontología profesional-, y cuando la gente cubre diferentes campos del conocimiento, a menudo encuentra útil, y algunas veces es esencial, usar representaciones visuales que sean especialmente útiles -o quizá incluso necesarias - para razonar en ciertos campos del conocimiento humano ( $v$. gr. el análisis espectral) o para razonar acerca de alguna clase concreta de fenómenos naturales ( $v$. gr. la rotación de Júpiter).

La tesis de este trabajo presupone que a pesar de la existencia e innegable importancia de técnicas especializadas para afrontar y resolver ciertas clases de problemas, es útil hablar acerca de la estructura general del pensamiento humano en relación con cuestiones y problemas de hecho. La tesis que este trabajo asume es que la metaestructura ${ }^{31}$ cognitiva implica técnicas de inferencia especializadas y es tanto más útil cuanto más importante intentar afinar el trabajo de esa metaestructura. Sólo el tiempo y la experimentación nos dirá si la hipótesis de la existencia de tal metaestructura general es un hecho o una ficción. Después de todo, es posible que las decisiones humanas acerca del cuándo y el cómo usar técnicas inferenciales especializadas sean cuestiones determinadas sólo por juicios personales e intuiciones irreductibles y de imposible análisis.

(Traducción de Igor Yánez Velasco)

${ }^{31}$ Esta metaestructura lo es sólo en un sentido amplio — porque incluso si tal metaestructura para pensamiento inferencial existe, las técnicas de inferencia especializadas no pueden deducirse o extraerse de ellaEsta metaestructura es, en el mejor de los casos, una estrategia general para el despliegue de diversos métodos especializados de dibujar inferencias. 